\title{
Dietary Forage Concentration Affects the Feed Sorting Behavior of Lactating Dairy Cows
}

\author{
T. J. DeVries, ${ }^{*}{ }^{1,2}$ K. A. Beauchemin, ${ }^{*}$ and M. A. G. von Keyserlingk $\dagger$ \\ *Agriculture and Agri-Food Canada, PO Box 3000, Research Centre, Lethbridge, Alberta, T1J 4B1, Canada \\ †Animal Welfare Program, The University of British Columbia, 2357 Main Mall, Vancouver, British Columbia, V6T 1Z4, Canada
}

\begin{abstract}
The objective of this study was to determine whether the amount of forage in a total mixed ration influences feed sorting by cows and whether the extent of this sorting changes as they adapt to a new diet. Six lactating Holstein cows, individually fed once per day, were provided each of 2 diets in a crossover design (dry matter basis): 1) a higher forage diet (HF; $62.3 \%$ forage), and 2) a lower forage diet (LF; $50.7 \%$ forage). Dry matter intake, feeding behavior, and sorting activity were monitored for each cow on each diet for $7 \mathrm{~d}$. Fresh feed and orts were sampled daily for each cow and subjected to neutral detergent fiber (NDF) and particle size analysis. The particle size separator contained 2 screens (18 and $9 \mathrm{~mm}$ ) and a bottom pan, resulting in 3 fractions (long, medium, and short). Sorting activity [for each fraction, NDF and physically effective NDF (peNDF)] was calculated as the actual intake expressed as a percentage of the predicted intake. Overall, sorting activity was greatest on the LF diet, with cows sorting for short particles but against long particles, medium particles, NDF, and peNDF. On the HF diet, cows sorted against long particles, NDF, and peNDF and sorted for short particles. Treatment $\times$ day interactions occurred for sorting for short particles and against peNDF, indicating that it took cows $1 \mathrm{~d}$ to adjust their sorting behavior to the LF diet. Cows on the LF diet consumed more dry matter but spent less time feeding, which resulted in a greater intake rate compared with cows on the $\mathrm{HF}$ diet. These results indicate that cows rapidly adjust their sorting behavior when subjected to a dietary change, and they exhibit more sorting for short particles and against long particles, NDF, and peNDF when fed an $\mathrm{LF}$ diet.
\end{abstract}

Key words: sorting, forage concentration, particle size

\footnotetext{
Received May 16, 2007.

Accepted August 19, 2007.

${ }^{1}$ Corresponding author: tdevries@kemptvillec.uoguelph.ca

${ }^{2}$ Current address: University of Guelph, Kemptville Campus, 830 Prescott Street, PO Box 2003, Kemptville, ON, Canada K0G 1J0.
}

\section{INTRODUCTION}

Providing lactating cows with rations in the form of a TMR, rather than separate feeding of concentrate and forage, is common practice on most commercial dairies. Nocek and Braund (1985) suggested that feeding a TMR is the optimal way to provide the balance of nutrients (including protein and structural and nonstructural carbohydrates) that ruminants need to maintain a stable and efficient microbial population. One concern with TMR feeding is that cows are able to selectively consume (sort) various feed components from their ration. Cows have been shown to preferentially sort for the grain component of a TMR and discriminate against the longer forage components (Leonardi and Armentano, 2003). Moreover, sorting of the diet can lead to the cows consuming an inconsistent ration (Stone, 2004). Cows engaged in sorting behavior are believed to consume higher amounts of grain and lower amounts of fiber, thereby increasing their risk for subacute ruminal acidosis (Cook et al., 2004; Stone, 2004). Alternatively, sorting of the TMR can reduce the nutritive value of the TMR remaining in the feed bunk, particularly in the later hours past the time of feed delivery (DeVries et al., 2005). As a result, cows without access to feed at the time when it is delivered may not be able to maintain the adequate nutrient intake needed to maintain high levels of milk production.

To date, the majority of research on feed sorting in dairy cattle has focused on changing the forage components of the TMR. In research by Leonardi and Armentano (2003), the effects on feed sorting of different quantities, qualities, and lengths of alfalfa hay were tested, without changing the proportion of concentrate in the diet. These researchers found that cows increased their sorting (discrimination against long particles) with more hay and with longer hay, whereas the quality of hay had no effect. Similar effects of particle size have been demonstrated by other researchers (e.g., Kononoff and Heinrichs, 2003; Kononoff et al., 2003; Onetti et al., 2004; Leonardi et al., 2005b). Despite this interest, one of the more basic questions that has received no attention is whether the composition (i.e., forage-to- 
concentrate ratio) of TMR influences the degree of feed sorting that occurs. Furthermore, no information is available on whether cows adjust their sorting behavior in response to a dietary change. This information is important because dairy producers typically sequentially offer several different rations (with varied forageto-concentrate ratios) over the course of the lactation cycle.

The objective of this study was to determine whether the forage concentration of the diet influences feed sorting by cows and whether the extent of this sorting changes as the cows adapt to a new diet. The hypothesis was that increasing the forage concentration of the diet increases sorting of the ration (i.e., against the forage and for the concentrate) and that sorting within both diets changes over time as cows adjust to a dietary change. This hypothesis was tested in an experiment with cows exposed to 2 different TMR, varying in forage concentration. The extent of sorting of each ration and the time it took cows to adjust their sorting behavior to each ration were measured.

\section{MATERIALS AND METHODS}

\section{Animals and Housing}

Six lactating Holstein cows, 2 primiparous and 4 multiparous (parity $=3.0 \pm 1.2$; mean $\pm \mathrm{SD}$ ), were used in the study. The animals were $221.5 \pm 46.1 \mathrm{DIM}$ at the beginning of the data collection period and had an average milk yield of $22.4 \pm 3.9 \mathrm{~kg} / \mathrm{d}$ over the course of the experiment. The cows were housed together in a freestall barn located at The University of British Columbia Dairy Education and Research Center (Agassiz, British Columbia, Canada) and were managed according to the guidelines set by the Canadian Council on Animal Care (1993). Cows were housed in a pen with 2 rows of 6 free stalls (mattress covered with sand); 1 row of free stalls was blocked so that each cow had access to 1 stall. Each day, cows were milked between 0730 and $0800 \mathrm{~h}$ in the morning and between 1730 and $1800 \mathrm{~h}$ in the afternoon. Milk yields were automatically recorded at each milking. Feed (TMR) and water were provided ad libitum by using roughage and water intake control feeders (Insentec B.V., Marknesse, the Netherlands). Each cow was assigned to her own roughage feeder and all cows shared 1 water feeder. Each day, the orts were cleaned out of the feed bins at $0700 \mathrm{~h}$ and feed was delivered at $0730 \mathrm{~h}$.

\section{Experimental Design and Diets}

The cows were divided into 2 groups of 3 , which were balanced according to DIM, milk production, and average parity $(2.3 \pm 1.4)$. These groups were created by
Table 1. Ingredients and chemical composition of the experimental TMR differing in forage-to-concentrate ratio

\begin{tabular}{|c|c|c|}
\hline Item & $\begin{array}{l}\text { Higher } \\
\text { forage } \\
\text { diet }^{1}\end{array}$ & $\begin{array}{l}\text { Lower } \\
\text { forage } \\
\text { diet }^{1}\end{array}$ \\
\hline \multicolumn{3}{|l|}{ Ingredient, $\%$ of $\mathrm{DM}$} \\
\hline Corn silage $^{2}$ & 24.4 & 19.8 \\
\hline Grass silage $^{2}$ & 37.9 & 30.9 \\
\hline Concentrate mash ${ }^{3}$ & 37.7 & 49.3 \\
\hline \multicolumn{3}{|l|}{ Chemical composition ${ }^{4}$} \\
\hline $\mathrm{DM}, \%$ & 41.4 & 47.6 \\
\hline $\mathrm{OM}, \%$ of $\mathrm{DM}$ & 89.5 & 89.5 \\
\hline $\mathrm{CP}, \%$ of DM & 18.3 & 18.9 \\
\hline $\mathrm{ADF}, \%$ of $\mathrm{DM}$ & 25.8 & 23.0 \\
\hline $\mathrm{NDF}, \%$ of $\mathrm{DM}$ & 42.7 & 37.5 \\
\hline NDF from forages, $\%$ of NDF & 79.3 & 70.4 \\
\hline $\mathrm{NE}_{\mathrm{L}},{ }^{5} \mathrm{Mcal} / \mathrm{kg}$ of $\mathrm{DM}$ & 1.58 & 1.60 \\
\hline
\end{tabular}

${ }^{1}$ Higher forage diet $=62.3 \%$ forage, $37.7 \%$ concentrate; lower forage diet $=50.7 \%$ forage, $49.3 \%$ concentrate.

${ }^{2}$ Corn silage: DM, $26.1 \%$; CP, 9.1\% DM; ADF, $28.5 \% \mathrm{DM}$; NDF, $44.0 \%$ DM. Grass silage: DM, 35.7\%; CP, $13.2 \%$ DM; ADF, $36.0 \%$ $\mathrm{DM}$; NDF, $61.2 \% \mathrm{DM}$.

${ }^{3}$ Supplied by Unifeed Ltd. (Chilliwack, British Columbia, Canada), containing (on an as-is basis): $34.0 \%$ steam-rolled barley, $20.3 \%$ fineground barley, $11.2 \%$ mill screenings, $10.0 \%$ rye and corn distillers grains, $8.0 \%$ Amipro (Unifeed Ltd.), $7.7 \%$ canola meal, 5.0\% limestone, $1.7 \%$ trace mineral and vitamin premix, $1.0 \%$ cane molasses, $0.7 \%$ salt, and $0.4 \%$ magnesium oxide.

${ }^{4}$ Values were obtained from chemical analysis of TMR samples.

${ }^{5} \mathrm{NE}_{\mathrm{L}}$ were calculated based on NRC (2001) equations.

blocking cows into groups of 2 cows (similar in parity, DIM, and milk production), and then randomly assigning the cows in these blocks to 1 of the 2 experimental groups.

During the week prior to receiving the experimental diets, the cows were housed together to facilitate social adaptation and to train them to access feed from their specific feeder. During this period, the cows remained on their standard high-production TMR consisting of $29.9 \%$ corn silage, $10.3 \%$ grass silage, $11.2 \%$ alfalfa hay, and $48.6 \%$ concentrate mash on a DM basis (DM, 51.0\%; $\mathrm{CP}, 17.5 \% \mathrm{DM}$; ADF, $20.8 \% \mathrm{DM}$; NDF, $35.5 \% \mathrm{DM}$; and $\mathrm{NE}_{\mathrm{L}}, 1.61 \mathrm{Mcal} / \mathrm{kg}$ ). After this time period, the cows were exposed to 2 dietary treatments (Table 1) in a crossover design. Initially, the cows were alternately assigned to 1 of 2 dietary treatments (assigned to alternate bins). The treatments were 1) a higher forage diet (HF; $62.3 \%$ forage, $37.8 \%$ concentrate), and 2) a lower forage diet (LF; $50.7 \%$ forage, $49.3 \%$ concentrate). The HF diet was mixed in a mixer wagon and delivered to each of the 6 feed bins. The LF diet was made by first adding a set amount of concentrate to the TMR in the bins designated to deliver the LF treatment. The feed was then dumped onto the cement floor in front of each bin and thoroughly mixed for $10 \mathrm{~min}$ by hand. After mixing was complete, the feed was placed back into its original bin. The amount of feed offered to each cow 
was adjusted daily to ensure a similar percentage of orts among animals and between treatments. Cows were kept on their respective treatments for $7 \mathrm{~d}$ and then switched to the other treatment and fed for an additional $7 \mathrm{~d}$.

\section{Measuring Feed and Water Intake and Behavior}

The Insentec feeders allowed for the continuous measurement of feeding and drinking behavior as well as feed and water intakes for all experimental animals, as validated by Chapinal et al. (2007). Each cow was fitted with a unique passive transponder (High-Performance ISO Half Duplex Electronic ID Tag, Allflex, StHyacinthe, Canada) that was attached to her ear tag. Each feeder was equipped with an access gate that was programmed to allow the specific cow to access the feed bin and 2 infrared sensors that recorded the presence of the cow at the feeder. A visit started when the antenna in the access gate detected the presence of the cow's transponder and the gate was lowered. A visit ended when interruption of the infrared sensors ended as the cow left the feeder and the gate closed. A computer recorded the cow number, feeder number, start time, end time, start weight, and end weight for each visit. From these data, we were able to determine the duration of each visit to the feeder, the amount of feed and water consumed (start weight - end weight) during each visit, and the rate of consumption for each visit. These data were then summarized to calculate water intake $(\mathrm{kg} / \mathrm{d})$, daily time spent feeding $(\mathrm{min} / \mathrm{d})$, daily DMI $(\mathrm{kg} / \mathrm{d})$, and average feeding rate $(\mathrm{kg} / \mathrm{min})$.

\section{Meal Analysis}

Visits to the feed intake system were separated into meals by using an individual meal criterion (minimum time interval that a cow was away from the feeder to be considered a meal) for each cow. These meal criteria were calculated by using a mixed distribution model, as outlined by DeVries et al. (2003). The meal criterion averaged $26.0 \pm 10.0$ (mean $\pm \mathrm{SD}$ ) min. Meal frequency, duration, and size were calculated by using these criteria.

\section{Feed Sampling and Analysis}

Representative samples of the TMR were taken daily in duplicate (one for chemical analysis, one for particle size separation) for each cow at the time of feed delivery (offered feed) and from the orts. Samples for particle size separation were immediately sieved by using the 2-screen (19- and 8-mm) Penn State Particle Separator (PSPS; Lammers et al., 1996). This separated the parti- cles into 3 particle size fractions: long particles $(>19$ $\mathrm{mm})$, medium particles $(<19 \mathrm{~mm},>8 \mathrm{~mm})$, and short particles $(<8 \mathrm{~mm})$. The separated fractions were then pooled by fraction, across animals, within day, and within treatment to create a composite for DM analysis.

Dry matter contents of the composite particle fractions and the samples for chemical analysis were determined by oven-drying at $55^{\circ} \mathrm{C}$ for $48 \mathrm{~h}$. The dried samples for chemical analysis were then ground to pass through a 1-mm screen (Brinkmann Mill, Brinkmann Instruments Co., Westbury, NY). The NDF contents of all the individual TMR samples (fresh feed and orts) were determined by using an Ankom ${ }^{200}$ Fiber Analyzer (Ankom Technology, Fairport, NY) according to the methodology supplied by the company, which is based on the methods described by Van Soest et al. (1991). Heat-stable $\alpha$-amylase and sodium sulfite were used in this procedure. The physical effectiveness factor (pef) of the TMR and orts were determined as the sum of the proportions of DM retained on 2 sieves (19 and 8 $\mathrm{mm}$ ) of the PSPS (Lammers et al., 1996). The physically effective NDF (peNDF) was calculated by multiplying the NDF content of the feed by the pef. The offered feed samples were also pooled by treatment, within period, and analyzed in duplicate for standard nutrients by using wet chemistry procedures $(\mathrm{n}=8$; Cumberland Valley Analytical Services Inc., Maugansville, MD). Grass silage and corn silage samples were taken in duplicate at the beginning of each treatment period and analyzed for standard nutrients by near-infrared spectroscopy ( $\mathrm{n}=8$; Unifeed Ltd., Chilliwack, British Columbia, Canada).

\section{Calculations and Statistical Analysis}

Sorting activity (for each fraction of the PSPS and for NDF and peNDF) was calculated as the actual intake of each variable expressed as a percentage of the predicted intake of that variable (Leonardi and Armentano, 2003). The predicted intake of an individual variable was calculated as the product of the DMI of the total diet multiplied by the DM percentage of that variable in the fed TMR. Values equal to $100 \%$ indicate no sorting, $<100 \%$ indicate selective refusals (sorting against), and $>100 \%$ indicate preferential consumption (sorting for).

Data for the DM content, NDF, particle size distribution, pef, and peNDF of the diets as well as the daily DMI, DM percentage of orts, NDF intake, peNDF intake, water intake, and feeding behavior data were summarized for each cow by treatment period and were analyzed by using PROC MIXED of SAS (SAS Institute, 1999). The model included the fixed effects of period, order, and treatment, the random effect of cow within order, and the residual error. 
Table 2. Particle size distribution of the experimental TMR differing in forage-to-concentrate ratio ${ }^{1}$

\begin{tabular}{lcccc}
\hline $\begin{array}{l}\text { Particle size distribution } \\
\text { and physically effective fiber, } \\
\text { \% of DM retained on the sieve }\end{array}$ & $\begin{array}{c}\text { Higher } \\
\text { forage }_{\text {diet }^{2}}\end{array}$ & $\begin{array}{c}\text { Lower } \\
\text { forage } \\
\text { diet }^{2}\end{array}$ & SE & $P<$ \\
\hline $19.0 \mathrm{~mm}$ & 19.5 & 10.0 & 0.5 & 0.001 \\
19.0 to $8.0 \mathrm{~mm}$ & 44.1 & 40.3 & 0.4 & 0.001 \\
$<8.0 \mathrm{~mm}$ & 36.4 & 49.7 & 0.4 & 0.001 \\
pef $^{3}$ & 0.64 & 0.50 & 0.004 & 0.001 \\
peNDF, $\%$ of DM & 26.7 & 18.9 & 0.3 & 0.001 \\
\hline
\end{tabular}

${ }^{1}$ Data are averaged over $7 \mathrm{~d}$ for 6 cows on each treatment.

${ }^{2}$ Higher forage diet $=62.3 \%$ forage, $37.7 \%$ concentrate; lower forage diet $=50.7 \%$ forage, $49.3 \%$ concentrate.

${ }^{3}$ pef $=$ physical effectiveness factor, determined as the proportion of particles retained by 2 sieves of the Penn State Particle Size Separator.

${ }^{4}$ peNDF $=$ physically effective NDF, measured as the NDF content of the TMR (DM basis) multiplied by the pef.

To test whether sorting of the experimental diets occurred, sorting activity for each fraction of the PSPS, $\mathrm{NDF}$, and peNDF was summarized by treatment and tested for a difference from 100 by using $t$-tests. Further, to test whether sorting activity differed between dietary treatments and over time, the data for sorting activity for each screen were summarized for each cow for each day on the treatment and were analyzed by using PROC MIXED of SAS (SAS Institute, 1999), treating day as a repeated measure. Compound symmetry was selected as the covariance structure on the basis of best fit according to Schwarz's Bayesian information criterion. The final model included the fixed effects of period, order, day, treatment, and day $\times$ treatment interaction, the random effect of cow within order, and the residual error. Day $\times$ period and day $\times$ order interactions were tested in the initial model and were not significant; therefore, they were dropped from the final analysis.

\section{RESULTS}

\section{Dietary Composition}

Nutrient composition and particle size distribution of the dietary treatments are reported in Tables 1 and 2 , respectively. The HF diet had a lower DM content than the $\mathrm{LF} \operatorname{diet}(\mathrm{SE}=0.2, P<0.001)$ but had a greater proportion of NDF (SE $=0.3, P<0.001$ ). Decreasing the amount of forage in the TMR decreased the DM retained on the 8 - and $19-\mathrm{mm}$ sieves and increased the DM found in the pan $(<8 \mathrm{~mm})$. The pef and peNDF were also reduced in the LF diet compared with the HF diet.

\section{Sorting}

Cows sorted against long particles $(>19 \mathrm{~mm})$ when fed the LF diet $(P<0.001)$ and tended to sort against
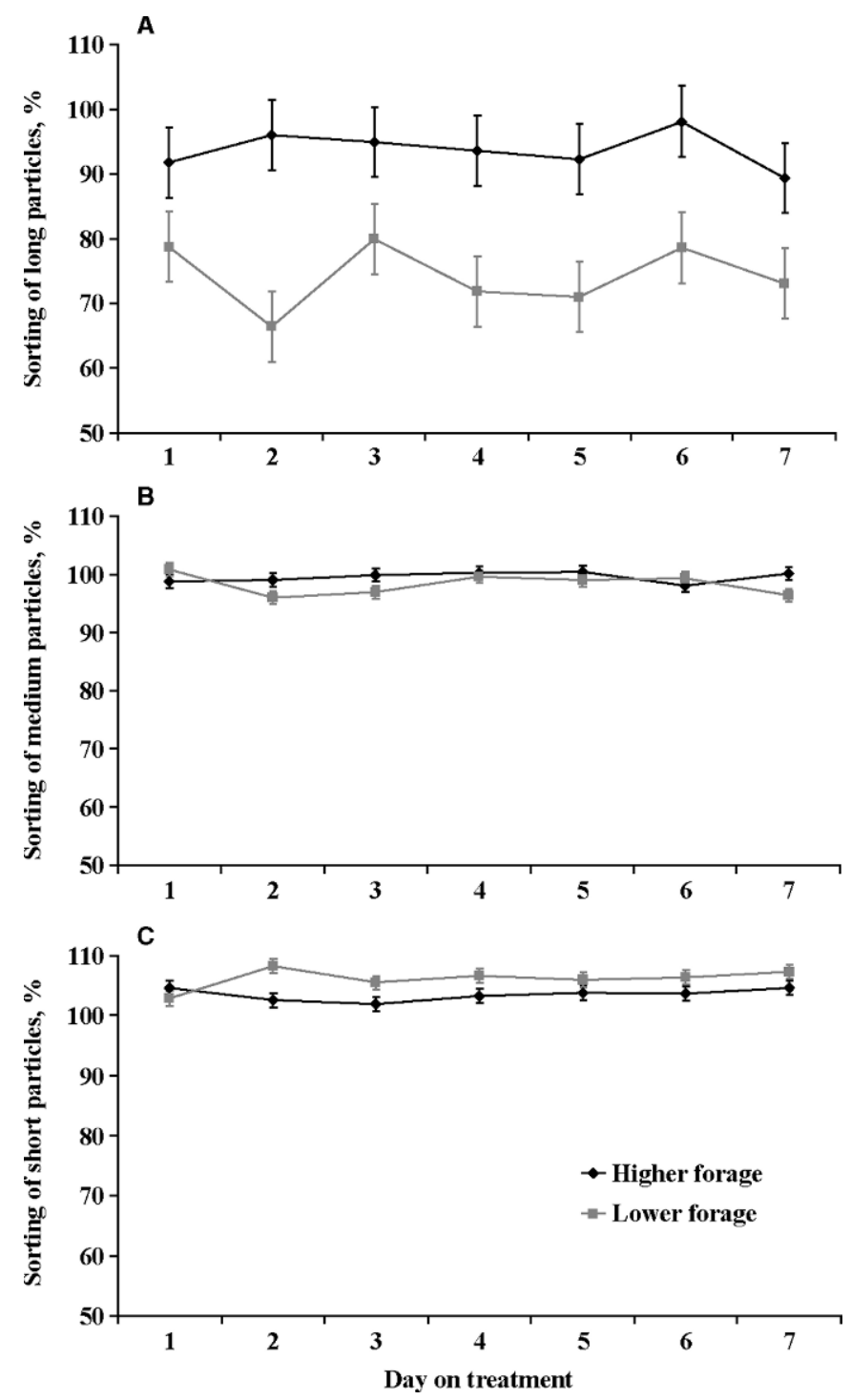

Figure 1. Sorting activity $[100 \times($ screen $\mathrm{i}$ intake/screen i predicted intake)] of cows on a higher forage diet (62.3\% forage, $37.7 \%$ concentrate) and a lower forage diet (50.7\% forage, $49.3 \%$ concentrate) for A) long particles ( $>19 \mathrm{~mm})$, B) medium particles $(<19 \mathrm{~mm},>8 \mathrm{~mm})$, and C) short particles $(<8 \mathrm{~mm})$. Data are averaged for 6 cows on each treatment. Sorting values equal to $100 \%$ indicate no sorting, $<100 \%$ indicate selective refusals (sorting against), and $>100 \%$ indicate preferential consumption (sorting for).

long particles when fed the HF diet $(P=0.07)$. The extent of sorting against long particles was greater for the LF diet compared with the HF diet $(P<0.001$; Figure 1A).

Cows on the HF diet did not sort for or against medium-length particles $(<19 \mathrm{~mm},>8 \mathrm{~mm})(P=0.3)$, whereas cows on the LF diet sorted against mediumlength particles $(P=0.001)$. As a result, more sorting occurred on the LF diet $(P<0.05$; Figure $1 \mathrm{~B})$, with a tendency for a treatment $\times$ day interaction $(P=0.08)$. 


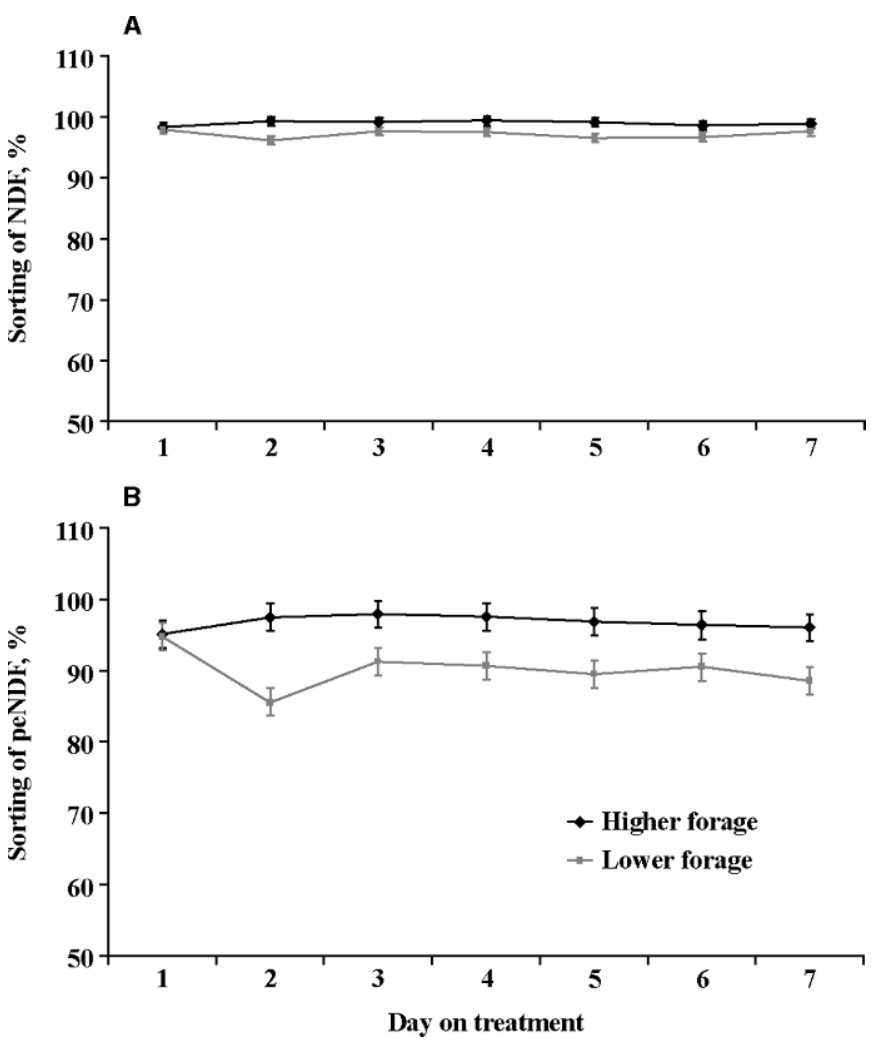

Figure 2. Sorting activity $[100 \times(\mathrm{n}$ intake/n predicted intake $)]$ of cows on a higher forage diet $(62.3 \%$ forage, $37.7 \%$ concentrate) and a lower forage diet (50.7\% forage, $49.3 \%$ concentrate) of A) NDF and B) physically effective NDF (peNDF). Data are averaged for 6 cows on each treatment. Sorting values equal to $100 \%$ indicate no sorting, $<100 \%$ indicate selective refusals (sorting against), and $>100 \%$ indicate preferential consumption (sorting for).

Cows sorted for short particles $(<8 \mathrm{~mm})$ when fed the $\mathrm{HF} \operatorname{diet}(P=0.001)$ and the LF $\operatorname{diet}(P<0.001)$. The extent of sorting for these short particles was greater on the LF diet compared with the HF $\operatorname{diet}(P<0.001$; Figure $1 \mathrm{C})$, with a treatment $\times$ day interaction $(P=$ $0.05)$.

Cows sorted against NDF when fed the HF $\operatorname{diet}(P=$ $0.009)$ and the LF $\operatorname{diet}(P<0.001)$. The extent to which cows sorted against NDF was greater on the LF diet compared with the HF diet $(P<0.001$; Figure $2 \mathrm{~A})$.

Cows sorted against peNDF when fed either the HF $\operatorname{diet}(P=0.03)$ or the LF $\operatorname{diet}(P<0.001)$. The extent of this type of sorting was greater on the LF diet compared with the HF diet $(P<0.001$; Figure 2B), with a trend for a treatment $\times$ day interaction $(P=0.1)$.

\section{Intakes and Behavior}

Cows had greater DMI on the LF diet (Table 3). Despite higher intake, their feeding time was reduced on this diet, resulting in a greater rate of intake compared
Table 3. Intake and feeding behavior measures on experimental TMR differing in forage-to-concentrate ratio ${ }^{1}$

\begin{tabular}{lcccc}
\hline & $\begin{array}{c}\text { Higher } \\
\text { forage }^{2} \\
\text { diet }^{2}\end{array}$ & $\begin{array}{c}\text { Lower } \\
\text { forage } \\
\text { diet }^{2}\end{array}$ & SE & $P$ \\
\hline Item & 19.9 & 22.2 & 0.7 & 0.03 \\
NMI, kg/d & 8.3 & 8.1 & 0.3 & 0.4 \\
peNDF intake, kg/d & 5.2 & 3.8 & 0.2 & $<0.001$ \\
Feeding time, $\mathrm{min} / \mathrm{d}$ & 220.5 & 193.3 & 39.1 & 0.02 \\
Feeding rate, $\mathrm{kg} / \mathrm{min}$ & 0.11 & 0.15 & 0.03 & 0.02 \\
Meal frequency, no./d & 7.4 & 7.1 & 0.4 & 0.5 \\
Total daily meal time, min/d & 277.3 & 257.6 & 47.6 & 0.07 \\
Meal duration, min/meal & 40.9 & 37.5 & 6.3 & 0.2 \\
Meal size, kg/meal & 3.0 & 3.3 & 0.3 & 0.08 \\
Water intake, kg/d & 73.1 & 80.6 & 4.8 & 0.14 \\
\hline
\end{tabular}

${ }^{1}$ Data are averaged over $7 \mathrm{~d}$ for 6 cows on each treatment.

${ }^{2}$ Higher forage diet $=62.3 \%$ forage, $37.7 \%$ concentrate; lower forage diet $=50.7 \%$ forage, $49.3 \%$ concentrate.

${ }^{3}$ peNDF $=$ physically effective NDF.

with when cows were provided the HF diet. The hourly DMI was consistently greater for the LF diet throughout the day (Figure 3A). The difference in hourly feeding times between diets was less pronounced during periods of peak feeding activity (Figure 3B). These differences in hourly DMI and feeding time translated into cows consuming the LF diet at a much greater feeding rate throughout the day, particularly during periods of peak feeding activity (Figure 3C). Despite no difference in meal number, cows tended to have shorter daily meal time and larger meals with the LF diet (Table 3). There was no difference in the percentage of feed refused (orts) by the animals $(\mathrm{HF}=16.6 \%, \mathrm{LF}=18.7 \% ; \mathrm{SE}=1.5$, $P=0.2$ ).

\section{DISCUSSION}

One concern with feeding a TMR is the ability of cows to selectively consume (sort) specific feed components from the ration. Dairy cattle are typically exposed to several TMR, varying in forage-to-concentrate ratio, over the course of their lactation cycle. We were therefore interested in investigating how this ratio influences the feed sorting behavior of lactating dairy cows. The 2 rations tested in this study were designed to be as similar as possible, with the exception of the forageto-concentrate ratio; namely, they contained the same components (corn silage, grass silage, and concentrate mash), and similar protein and energy contents. Because of the increased content of silage, the HF diet was lower in DM concentration and greater in NDF concentration. Conversely, the lower forage proportion of the LF diet resulted in less DM retained on the 8and $19-\mathrm{mm}$ sieves and more DM found in the pan $(<8$ $\mathrm{mm}$ ) of the PSPS. These changes in particle size distri- 

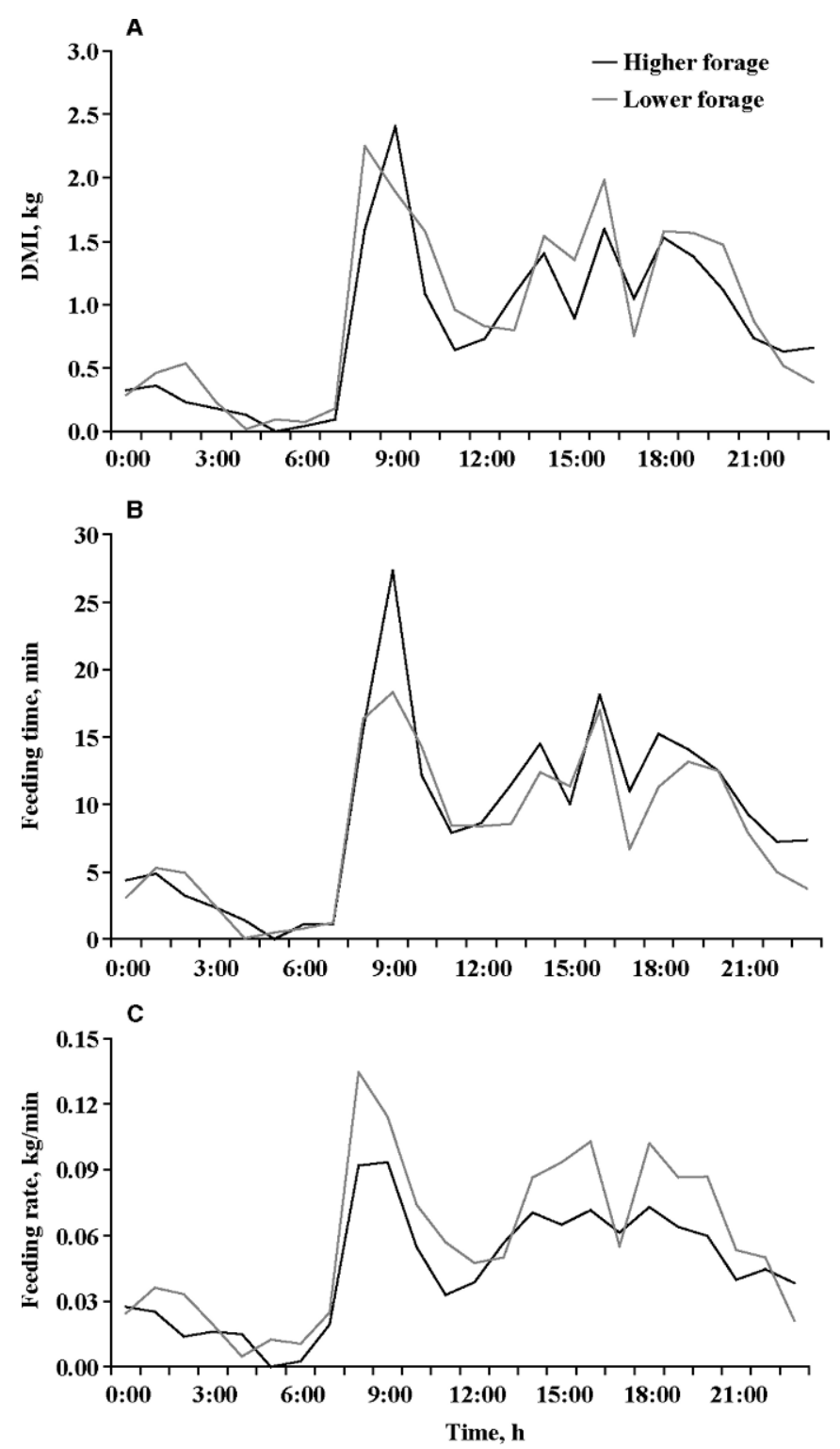

Figure 3. Hourly averages for A) DMI (kg) B) feeding time (min), and C) feeding rate $(\mathrm{kg} / \mathrm{min})$ for cows fed a higher forage diet $(62.3 \%$ forage, $37.7 \%$ concentrate) and a lower forage diet (50.7\% forage, $49.3 \%$ concentrate) diet. Data are averaged over $7 \mathrm{~d}$ for 6 cows on each treatment.

bution and NDF content resulted in the pef and peNDF being lower for the LF diet compared with the HF diet.

The results clearly indicate that, regardless of dietary treatment, sorting of the feed did occur. Similar to previous findings (e.g., Leonardi and Armentano, 2003; DeVries et al., 2005), cows were clearly sorting against long particles, and hence NDF and peNDF, and sorting for shorter particles. Considering the ingredients used in these diets, it is apparent that the cows were primarily sorting against the long silage particles and for the concentrate mash, which made up the majority of the short particle fraction.

Even though several researchers have shown that sorting against long particles and NDF can be reduced by changing the characteristics of forages within a TMR (e.g., particle size: Kononoff and Heinrichs, 2003; Kononoff et al., 2003; Leonardi and Armentano, 2003; Onetti et al., 2004; Leonardi et al., 2005b), no one has looked at how the proportion of forage in the diet influences sorting behavior. Our results indicate that cows easily discriminated against long particles, NDF, and peNDF, and selected for short particles when fed an LF diet. This finding contradicts our hypothesis that cows would sort more with increased forage in the diet (i.e., the HF treatment). We assumed that cows would be highly motivated to sort for the concentrate portion of their TMR, especially when availability of concentrate was limited. Thus, we assumed that decreasing the concentrate portion in the TMR would motivate cows to sort for concentrate and against forage. The increased sorting of the LF diet indicates, however, that a ration with higher a proportion of concentrate may be more easily sorted, simply because the concentrate content is more accessible.

The amount of feed offered can influence the degree of feed sorting (Leonardi and Armentano, 2007). The percentage of orts, however, was similar between treatments; therefore, the amount of feed offered would not have influenced the degree of feed sorting in our study.

Leonardi et al. (2005a) showed a reduction in the amount of feed sorting (against long particles) when water was added to a dry diet $(80 \% \mathrm{DM})$. Thus, the greater moisture content of the $\mathrm{HF}$ ration may have contributed to the decreased sorting of the HF diet. It should be noted, however, that the "wet" diet described by Leonardi et al. (2005a) was much drier (64\% DM) than both diets used in the present study. It could be speculated that moisture content would have had less of an effect on the sorting of the diets fed in the present study, particularly because these diets were both silage based, with high moisture contents. Further research is needed to assess how moisture content affects the sorting of higher moisture diets.

We also hypothesized that cows would adjust their sorting behavior over time as they adapted to a dietary change. This hypothesis was also refuted because cows quickly adjusted their sorting behavior. For both treatments, cows consistently sorted against long particles and NDF throughout the 7-d treatment period. Treatment $\times$ day interactions revealed that cows took $1 \mathrm{~d}$ to adjust their sorting for short particles and against peNDF when switched to the LF diet. There was also a treatment $\times$ day interaction for sorting of medium particles. However, this finding is not very meaningful 
because there was minimal sorting of medium particles on either diet. The interaction is most likely the result of day-to-day variation in sorting behavior. Leonardi and Armentano (2003) are the only other group to report changes in sorting behavior after introduction to a new diet. However, these researchers measured sorting only on $\mathrm{d} 1$ and 6 , and were unable to describe when the change occurred, unlike in the present study. Our study is the first to show the rapid acclimation in sorting behavior by lactating cows. This information may be of particular relevance to cows in early lactation, which are typically switched from an HF to an LF diet immediately upon calving. If early-lactation cows sort in a similar manner, sorting of an LF diet coupled with rapidly increasing DMI in the days following calving will likely exacerbate the intake of short particles and refusal of long particles, NDF, and peNDF. This may result in increased VFA production and low buffering capacity in the rumen, factors that increase the risk of subacute ruminal acidosis (Cook et al., 2004; Stone, 2004).

Intuitively, one would predict that sorting behavior would slow the eating rate, but again our results provide evidence that the opposite occurs. Cows consuming the LF diet ate at a greater rate and in a shorter time period. Johnson and Combs (1992) also found that cows consuming a $50 \%$ forage diet spent less time eating than those fed a $74 \%$ forage diet. In contrast, Voelker et al. (2002) reported similar feeding times for cows fed a 67 or $44 \%$ forage diet. These latter authors suggest that such discrepancies in feeding times may be the result of differences in dietary particle size. However, neither of these previous studies reported dietary particle size. Interestingly, Voelker et al. (2002) did report that the eating time per kilogram of DMI was lesser for the cows fed a $44 \%$ forage diet, indicating that these cows consumed their DM faster, similar to the greater feeding rates on the LF diet seen in the present study. Allen (2000) stated that dietary factors that increase eating time could decrease the time available for ruminating, thereby increasing the filling effect of the diet. Similarly, in our study, the HF diet took longer to consume, likely because of its high NDF content and longer particle size. These factors may have contributed to an increased filling effect, accounting for the lower DMI on the HF diet. Both Johnson and Combs (1992) and Voelker et al. (2002) found DMI to be lower on their higher forage diets. The effect of lesser DMI as a result of increased forage concentration is well founded, as demonstrated in a meta-analysis by Allen (2000), who showed that as dietary NDF content increases through substitution of grain with forage, DMI generally declines. In our study the intake of NDF was similar between the 2 diets, as a result of greater overall DMI on the LF diet. Voelker et al. (2002) found NDF intake to be greater on their higher forage diet, which resulted from a smaller difference in DMI between diets compared with that seen in the present study. Despite no difference in NDF intake, the intake of peNDF was much lower on the LF diet because of differences in particle size of the diets and the greater degree of sorting against peNDF.

Johnson and Combs (1992) found no effect of forage concentration on meal number, but did report that cows had longer meals when consuming a $74 \%$ forage diet compared with a $50 \%$ forage diet. Similarly, in the present study, we found no effect of diet on meal number. Although cows tended to have longer total daily meal times when on the HF diet, there was no difference in meal length. This discrepancy may be the result of differences in meal calculation. Unfortunately, we can only speculate that Johnson and Combs (1992) used a very short meal criterion because they failed to report how they calculated meal numbers.

The high consumption rates of the LF diet observed during the time period following feed delivery is of concern, given the higher degree of sorting of this ration. DeVries and von Keyserlingk (2005) demonstrated that the motivation to feed is greatest immediately following the delivery of fresh feed, a time when competition at the feed bunk is also greatest. In situations where cows are consuming an LF diet in a highly competitive environment, dominant cows may be rapidly consuming increased amounts of fermentable carbohydrates and low amounts of physically effective fiber, putting them at risk for subacute ruminal acidosis. Alternatively, subordinate cows that are unable to access the bunk during this time may be forced to access feed at a later time, when the nutrient profile of the remaining feed may not match their specific requirement. Feed bunk management strategies, including additional space or use of feed stalls, make it easier for all cows to access feed at any given time, and will act to reduce the betweencow variation in TMR consumed (DeVries and von Keyserlingk, 2006). The fact that feed was delivered only once per day in the present study must not be overlooked. Previous research on feeding frequency has indicated that delivery of feed at least 2 times per day will improve access to feed, reduce feed sorting, and reduce between-cow variation in TMR consumed (DeVries et al., 2005).

\section{CONCLUSIONS}

Cows rapidly adjusted their sorting behavior when subjected to a dietary change and exhibited more sorting for short particles and against long particles, NDF, and peNDF when fed an LF diet. Feeding an LF diet also increased DMI, decreased feeding time, and in- 
creased feeding rate, particularly during the time period following feed delivery. These sorting and feeding behavior results suggest that feeding an LF diet may increase the risk of cows' succumbing to subacute rumen acidosis. These results indicate that measures such as reducing competition at the feed bunk and increasing the frequency of feed delivery must be considered when feeding an LF diet to reduce sorting and the between-cow variation in composition of TMR consumed.

\section{ACKNOWLEDGMENTS}

We thank the staff and students at The University of British Columbia's Dairy Education and Research Centre. In particular we thank Doug Veira and Audrey Nadalin for their help with the feed sample drying. We also thank Bev Farr and Sheila Frank of the Lethbridge Research Centre for their assistance in performing laboratory analyses. Trevor DeVries was supported by a Natural Sciences and Engineering Research Council of Canada Visiting Fellowship. The project was funded through joint contributions from the Westgen Endowment Fund and Investment Agriculture Foundation of British Columbia.

\section{REFERENCES}

Allen, M. S. 2000. Effects of diet on short-term regulation of feed intake by lactating dairy cattle. J. Dairy Sci. 83:1598-1624.

Canadian Council on Animal Care. 1993. Guide to the Care and Use of Experimental Animals. Vol. 1. E. D. Olfert, B. M. Cross, and A. A. McWilliam, ed. Can. Counc. Anim. Care, Ottawa, Canada.

Chapinal, N., D. M. Veira, D. M. Weary, and M. A. G. von Keyserlingk. 2007. Validation of a system for monitoring individual feeding and drinking behavior and intake in group housed cattle. J. Dairy Sci. 90:5732-5736.

Cook, N. B., K. V. Nordlund, and G. R. Oetzel. 2004. Environmental influences on claw horn lesions associated with laminitis and subacute ruminal acidosis in dairy cows. J. Dairy Sci. 87(E Suppl.):E36-E46.

DeVries, T. J., and M. A. G. von Keyserlingk. 2005. Time of fresh feed delivery affects the feeding and lying patterns of dairy cows. J. Dairy Sci. 88:625-631.
DeVries, T. J., and M. A. G. von Keyserlingk. 2006. Feed stalls affect the social and feeding behavior of lactating dairy cows. J. Dairy Sci. 89:3522-3531.

DeVries, T. J., M. A. G. von Keyserlingk, and K. A. Beauchemin. 2005. Frequency of feed delivery affects the behavior of lactating dairy cows. J. Dairy Sci. 88:3553-3562.

DeVries, T. J., M. A. G. von Keyserlingk, D. M. Weary, and K. A. Beauchemin. 2003. Measuring the feeding behavior of lactating dairy cows in early to peak lactation. J. Dairy Sci. 86:3354-3361.

Johnson, T. R., and D. K. Combs. 1992. Effects of inert rumen bulk on dry matter intake in early and midlacation cows fed diets differing in forage content. J. Dairy Sci. 75:508-519.

Kononoff, P. J., and A. J. Heinrichs. 2003. The effect of corn silage particle size and cottonseed hulls on cows in early lactation. J. Dairy Sci. 86:2438-2451.

Kononoff, P. J., A. J. Heinrichs, and H. A. Lehman. 2003. The effect of corn silage particle size on eating behavior, chewing activities, and rumen fermentation in lactating dairy cows. J. Dairy Sci. 86:3343-3353.

Lammers, B. P., D. R. Buckmaster, and A. J. Heinrichs. 1996. A simple method for the analysis of particle sizes of forage and total mixed rations. J. Dairy Sci. 79:922-928.

Leonardi, C., and L. E. Armentano. 2003. Effect of quantity, quality, and length of alfalfa hay on selective consumption by dairy cows. J. Dairy Sci. 86:557-564.

Leonardi, C., and L. E. Armentano. 2007. Feed selection by dairy cows fed individually in a tie-stall or as a group in a free-stall barn. J. Dairy Sc. 90:2386-2389.

Leonardi, C., F. Giannico, and L. E. Armentano. 2005a. Effect of water addition on selective consumption (sorting) of dry diets by dairy cattle. J. Dairy Sci. 88:1043-1049.

Leonardi, C., K. J. Shinners, and L. E. Armentano. 2005b. Effects of different dietary geometric mean particle length and particle size distribution of oat silage on feeding behavior and productivity performance of dairy cattle. J. Dairy Sci. 88:698-710.

Nocek, J. E., and D. G. Braund. 1985. Effect of feeding frequency on diurnal dry matter and water consumption, liquid dilution rate, and milk yield in first lactation. J. Dairy Sci. 68:2238-2247.

Onetti, S. G., S. M. Reynal, and R. R. Grummer. 2004. Effect of alfalfa forage preservation method and particle length on performance of dairy cows fed corn silage-based diets and tallow. J. Dairy Sci. 87:652-664.

SAS Institute. 1999. SAS User's Guide. SAS Institute Inc., Cary, NC.

Stone, W. C. 2004. Nutritional approaches to minimize subacute ruminal acidosis and laminitis in dairy cattle. J. Dairy Sci. 87:E13-E26.

Van Soest, P. J., J. B. Robertson, and B. A. Lewis. 1991. Methods for dietary fiber, neutral detergent fiber and non-starch polysaccharide in relation to animal nutrition. J. Dairy Sci. 74:35833597.

Voelker, J. A., G. M. Burato, and M. S. Allen. 2002. Effects of pretrial milk yield on responses of feed intake, digestion, and production to dietary forage concentration. J. Dairy Sci. 85:2650-2661. 